\title{
Counting asbestos bodies in bronchoalveolar lavage: trend analysis and a systematic review
}

\author{
Valerie Nuyts ${ }^{*}$, Hadewijch Vanhooren, Kristiaan Nackaerts, Ben Nemery \\ From Methods in Epidemiology Symposium \\ Leuven, Belgium. 17 September 2015
}

\section{Background and aims}

Asbestos bodies $(\mathrm{AB})$ in bronchoalveolar lavage (BAL) can be quantified by light microscopy and their concentration is indicative of past cumulative asbestos exposure. The objective of this retrospective study was to assess clinical and exposure characteristics, as well as possible time trends, among patients in whom $A B$ had been measured in BAL. We also conducted a systematic review of the literature on the subject.

\section{Methods}

BAL samples were available from 548 subjects over a period from January 1997 until December 2013. The processing of samples and the microscopic analysis were done by a single expert and $75 \%$ of samples came from a single tertiary care hospital, allowing clinical and exposure data to be extracted from patient files. MEDLINE and Embase databases were searched for relevant articles on the subject, and 45 relevant articles were selected.

\section{Results}

The study population ( $96 \%$ males) had a mean age of 62.2 (12.3) years. AB were detected in $56.4 \%$ of the samples, giving a median concentration of 0.5 AB.ml-1 (95th percentile: $25 \mathrm{AB} . \mathrm{ml}-1$; highest value: $164.5 \mathrm{AB}$. ml-1). The $\mathrm{AB}$ concentration exceeded $1 \mathrm{AB} \cdot \mathrm{ml}-1$ in $40.1 \%$ and 5 AB.ml- 1 in $18.6 \%$ of the samples. A significant decrease in $A B$ concentrations was apparent over the years. High $A B$ concentrations corresponded to high reported exposures to asbestos. $\mathrm{AB}$ concentrations were higher among patients with pleural disorders when compared to other disease groups. A systematic review of 45 published articles confirmed these observations: groups with occupational exposure to asbestos and patients

\footnotetext{
KU Leuven, Leuven, Belgium
} creativecommons.org/licenses/by/4.0), which permits unrestricted use, distribution, and reproduction in any medium, provided the original work is properly cited. The Creative Commons Public Domain Dedication waiver (http://creativecommons.org/publicdomain/ zero/1.0/) applies to the data made available in this article, unless otherwise stated. 